\title{
Increased mitochondrial respiration maintains the mitochondrial membrane potential and promotes survival of cerebellar neurons in an endogenous model of glutamate receptor activation
}

\author{
Octavio García, ${ }^{*}+$ Angeles Almeida, $\uparrow$ Lourdes Massieu $\ddagger$ and Juan P. Bolaños*,1 \\ *Departamento de Bioquímica y Biología Molecular, Universidad de Salamanca, Campus Miguel de Unamuno, Salamanca, Spain \\ $\dagger$ Unidad de Investigación, Hospital Universitario de Salamanca, Salamanca, Spain \\ $\ddagger$ Departamento de Neurociencias, Instituto de Fisiología Celular, Universidad Nacional Autónoma de México, México D.F., México
}

\begin{abstract}
It is thought that the combination of extracellular glutamate accumulation and mitochondrial damage is involved in neuronal death associated with brain ischemia and hypoglycemia, and some neurodegenerative diseases such as Huntington's disease. However, the mechanism whereby those two factors interact together to trigger neurodegeneration in this and other neurodegenerative disorders is still elusive. Here, we have addressed this issue using a model of mild and sustained accumulation of extracellular glutamate in cerebellar cultured neurons, which are mostly glutamatergic and commonly used to study glutamate neurotoxicity. The resulting stimulation of glutamate receptors triggered $a \sim 50 \%$ persistent increase in mitochondrial respiration that was associated with free radicals formation, and which was found to be necessary to prevent the collapse of the mitochondial membrane potential
\end{abstract}

$\left(\Delta \psi_{\mathrm{m}}\right)$ and apoptotic cell death. In fact, hampering the glutamate-mediated increase in mitochondrial respiration with an inhibitor of the mitochondrial respiratory chain stopped neurons from producing free radicals, but led them to undergo rapid and profound $\Delta \psi_{\mathrm{m}}$ collapse and apoptotic cell death. Thus, we suggest that the formation of reactive oxygen species by glutamate receptor activation is the unavoidable consequence of an increase in the mitochondrial respiration aimed to prevent $\Delta \psi_{\mathrm{m}}$ collapse and neurodegeneration. These results may be relevant to understand the pathophysiology of those neurodegenerative diseases associated with both mitochondrial respiratory chain and glutamate transporter defects.

Keywords: free radicals, glutamate, glutathione, mitochondria, neurodegeneration, neuroprotection.

J. Neurochem. (2005) 92, 183-190.
Glutamate receptor over-stimulation following extracellular accumulation of the amino acid has been involved in the pathophysiology associated with brain ischemia, hypoglycemia, and certain neurodegenerative disorders, such as Huntington's disease (Bittigau and Ikonomidou 1997). It is well known that glutamate neurotoxicity is exacerbated by mitochondrial failure, and that even low concentrations not sufficient to induce neuronal death become neurotoxic in the presence of mitochondrial toxins. During the ischemic episode there is a prompt decline in energy levels and a large increase in the extracellular concentration of glutamate and aspartate (Benveniste et al. 1984). In addition, prolonged decreases in mitochondrial activity after brain ischemia have been described (Anderson and Sims 1999). Diminished activity of the different components of the mitochondrial electron transport chain has also been linked to Alzheimer's, Parkinson's and Huntington's diseases, suggesting that mitochondrial damage is involved in the pathogenesis of these disorders. The regulation of the extracellular concentrations of glutamate depends on its removal by transporter proteins. As glutamate transporters are energy and sodium

Received July 5, 2004; revised manuscript received August 29, 2004; accepted September 7, 2004.

Address correspondence and reprint requests to Octavío Garcia, MSc, Departamento de Neurociencias, Instituto de Fisiología Celular, Universidad Nacional Autónoma de México, Apartado Postal 70-253, 04510 México D.F., México. E-mail: ogarcia@ifc.unam.mx

${ }^{1}$ The present address of Juan P. Bolaños is Centro Nacional de Investigaciones Cardiovasculares (CNIC), Madrid, Spain.

Abbreviations used: 7-AAD, 7-amino-actinomycin D; DCF, dichlorofluorescein; $\Delta \psi_{\mathrm{m}}$, mitochondrial membrane potential; JC-1, 5,5',6,6'tetrachloro-1, 1',3,3'-tetraethylbenzimidazolylcarbocyanine iodide; LNAME, L- $N^{\omega}$-nitroargininemethyl ester; 3-NP, 3-nitropropionic acid; PDC, L-trans-pirrolydine 2,4-dicarboxylate; ROS, reactive oxygen species. 
dependent carriers that can operate in the reverse direction during neuronal energy failure, mitochondrial damage would potentiate the excitotoxic neuronal death during extracellular glutamate accumulation (Benveniste et al. 1984; Rossi et al. 2000). In fact, in vivo administration of L-trans-pirrolydine 2,4-dicarboxylate (PDC) - an inhibitor of glutamate uptake seen to increase extracellular concentration of glutamate in the striatum and the hippocampus - does not cause neuronal damage in rats (Massieu et al. 1995). Similar results have been found in cultured cerebellar granule neurons (Cebers et al. 1999; García and Massieu 2001). However, the administration of PDC to rats previously treated with subtoxic concentrations of the mitochondrial toxin 3-nitropropionic acid (3-NP) or the glycolysis inhibitor, iodoacetate induces large lesions into those brain areas (SánchezCarbente and Massieu 1999; Massieu et al. 2000), in good agreement with previous in vivo and in vitro studies showing that metabolic inhibition potentiates glutamate neurotoxicity (Novelli et al. 1988; Greene and Greenamyre 1995). These results suggest that, whereas glutamate, at the concentration reached in the extracellular space during these conditions, or mitochondrial impairment per se are insufficient factors to cause neurodegeneration, the combination of both trigger neuronal death. However, the underlying mechanism responsible for such synergistic effect is yet unknown.

In order to address this issue, we have used a wellestablished model of glutamate receptor activation based on the inhibition of glutamate uptake, which leads to a mild and sustained increase in the extracellular concentration of glutamate (García and Massieu 2001). We have found evidence consistent with the notion that glutamate receptor activation triggers an enhancement in mitochondrial oxygen consumption focused to prevent the loss of mitochondrial membrane potential $\left(\Delta \psi_{\mathrm{m}}\right)$, and the apoptotic neuronal death. We believe that these results may be of relevance to understand the mechanism of neurotoxicity in certain pathophysiological conditions, such as ischemia, hypoglycemia, or Huntington's disease, in which, in addition to mutated Huntingtin, decreased activity of complexes II, III and IV of the electron transport chain (Gu et al. 1996; Browne et al. 1997; Panov et al. 2002) and decreased glutamate transporter (Arzberger et al. 1997) has been described.

\section{Experimental procedures}

\section{Culture of cerebellar neurons}

Cerebellar granule neurons in primary culture were obtained from 7-8-day-old Wistar rats as described (García and Massieu 2001). Cells were seeded at $1.5 \times 10^{6}$ cells/well in 6-wells Nunc (Roskilde, Denmark) plastic Petri dishes previously coated with poly D-lysine $(15 \mu \mathrm{g} / \mathrm{mL})$ and incubated for 9 days in vitro in Basal Eagle's Medium, supplemented with $10 \%$ fetal bovine serum, L-glutamine (2 mM), penicillin $(100 \mathrm{U} / \mathrm{mL})$, streptomycin $(100 \mu \mathrm{g} / \mathrm{mL})$, amphotericin B $(0.25 \mu \mathrm{g} / \mathrm{mL})$, and $\mathrm{KCl}(25 \mathrm{~mm})$. Glucose $(5 \mathrm{mM})$ and cytosine arabinoside $(10 \mu \mathrm{M})$ were added $24 \mathrm{~h}$ after plating to inhibit the proliferation of non-neuronal cells.

\section{Cell treatments}

After 9 days in vitro, neurons were incubated in the presence of the glutamate uptake inhibitor PDC $(500 \mu \mathrm{M})$ or the succinate dehydrogenase inhibitor 3-NP $(500 \mu \mathrm{M})$, either alone or in combination, as previously described (García and Massieu 2003), for different time periods ( $5 \mathrm{~min}$ to $4 \mathrm{~h}$ ). In some experiments, cells were incubated in the presence of MK-801 $(10 \mu \mathrm{M})$, superoxide dismutase $(100 \mathrm{U} / \mathrm{mL})$, catalase $(100 \mathrm{U} / \mathrm{mL})$ and $N^{\omega}$-nitro-L-arginine monomethyl ester (L-NAME, $1 \mathrm{~mm}$ ), which were added $5 \mathrm{~min}$ prior to PDC addition.

Flow-cytometric analyses of mitochondrial membrane potential and apoptotic death

$\Delta \psi_{\mathrm{m}}$ and apoptotic death were determined in the same cellular suspension by flow cytometry, essentially as previously described (Almeida et al. 2001; García-Nogales et al. 2003). Briefly, cells were first smoothly scraped off the plates in order to minimize cellular disruption, and then they were incubated with $5,5^{\prime}, 6,6^{\prime}$ tetrachloro-1, 1',3,3'-tetraethylbenzimidazolylcarbocyanine iodide (JC-1, $3 \mu \mathrm{M}$ ), followed by incubation with APC-conjugated annexin- $\mathrm{V}$ and 7-amino-actinomycin D (7-AAD) (Becton-Dickinson Biosciences, Franklin Lakes, NJ, USA). Data acquisition was performed using a FACScalibur flow cytometer (Becton Dickinson Biosciences), equipped with a $15 \mathrm{~mW}$ argon ion laser tuned at $488 \mathrm{~nm}$, using the CellQuest software (Becton-Dickinson Biosciences). Photomultiplier settings were adjusted to detect JC-1 monomer fluorescence signals on the FL1 detector (green fluorescence, centered around $525 \mathrm{~nm}$ ), and JC-1 aggregate fluorescence signals on the FL2 detector (red fluorescence, centered around $590 \mathrm{~nm}$ ). Data analysis was performed using the Paint-A-Gate PRO software (Becton-Dickinson Biosciences). Mean fluorescence intensity values for FL1 and FL2, expressed as relative linear fluorescence channels (arbitrary units scaled from channel 010 000) were obtained for all experiments. The relative aggregate/ monomer (red/green) fluorescence intensity values were used for $\Delta \psi_{\mathrm{m}}$ data presentation. Preliminary experiments focused to validate this protocol were performed using the mitochondrial permeability pore inhibitor, cyclosporin A (10 $\mu \mathrm{M}$ for $15 \mathrm{~min})$, which showed no effect on FL2/FL1 ratio ( 1.3 a.u., not shown) when compared to untreated cells. Furthermore, the FL2/FL1 ratio values $(\sim 0.2$ a.u., not shown) obtained after adding FCCP $(5 \mu \mathrm{M})$ to the cell suspensions were similar to those obtained with antimycin A $(10 \mu \mathrm{g} / \mathrm{mL})$. Annexin V-APC and 7-AAD signals were acquired on the FL4 and FL3 channels, respectively, to quantitatively determine the percentage of apoptotic cells. In all cases, the analyzer threshold was adjusted on the FSC channel to exclude most of the subcellular debris in order to reduce the background noise due to the cellular disruption during scrapping. To exclusively quantify cells showing the early apoptotic feature phosphatidylserine translocation, we determined those annexin $\mathrm{V}$ positive cells that were 7-AAD negative. As 7-AAD only binds DNA to those cells having a nonintact plasma membrane (due to both disruption during scrapping 
and necrosis by the treatments), we considered to be apoptotic those cells that were annexin $\mathrm{V}^{+}-7-\mathrm{AAD}^{-}$.

\section{GSH, NADPH and NADH determinations}

GSH concentrations were measured by the enzymatic method described by Tietze (1996) with the modifications described by Dringen and Hamprecht (1996) (see also García-Nogales et al. 2003). NADH and NADPH concentrations were measured in the cells exactly as described by García-Nogales et al. (2003).

\section{Determination of oxygen consumption}

Oxygen consumption was determined with a Clark-type electrode (Rank Brothers, Cambridge, UK) in the intact, resuspended cells at $37^{\circ} \mathrm{C}$ in buffered Hanks' solution. The rates of oxygen consumption were calculated from the slopes (monitored for at least $15 \mathrm{~min}$ per trace), and expressed as nmol of oxygen consumed per minute per $0.5 \times 10^{6}$ cells.

\section{Measurement of reactive oxygen species}

The formation of intracellular reactive oxygen species (ROS) was assessed using the dye carboxy- $\mathrm{H}_{2}$ DCFDA $(20 \mu \mathrm{M})$ (Hempel et al. 1999). Its desterification product, carboxy-dichlorofluorescein (carboxy- $\mathrm{H}_{2} \mathrm{DCF}$ ), is cleaved by esterases and remains entrapped within the cells, hence being prone to ROS-mediated oxidation to fluorogenic carboxy-DCF (Hempel et al. 1999). To evaluate the formation of superoxide anion, we used hydroethidine, which is specifically oxidized by superoxide as previously reported (Bindokas et al. 1996). Thus, after the incubation periods, cells were washed and further incubated in the presence of hydroethidine $(3.2 \mu \mathrm{M})$ for $20 \mathrm{~min}$ at $37^{\circ} \mathrm{C}$. After fixing and mounting the cells in coverslips, the number of fluorescent neurons was counted in 10 different fields per coverslip from three independent experiments with the aid an image analyzer (NIH Image 1.6 for Macintosh) and expressed as percentages.

\section{Determination of complex I activity}

For the determination of enzyme activity, cells were washed with ice-cold phosphate-buffered saline and collected, centrifuged and resuspended in $300 \mu \mathrm{L}$ of $0.1 \mathrm{M}$ potassium phosphate buffer (pH 7.0). Cell suspensions (containing approximately $3-4 \mathrm{mg}$ of protein $/ \mathrm{mL}$ ) were frozen and thawed three times to ensure cell lysis. Complex I (NADH-ubiquinone oxidoreductase) activity was measured by determining the rotenone-sensitive NADH oxidation using ubiquinone-5 (coenzyme Q1, Sigma, St Louis, MO, USA) as the electron acceptor (Ragan et al. 1987) in a Hitachi U2000 spectrophotometer (Hitachi Ltd, Tokio, Japan). Enzyme activity is expressed as nanomoles per minute per milligram of protein.

\section{Protein determinations}

Protein concentrations were determined in cells solubilized with $0.1 \mathrm{~m} \mathrm{NaOH}$ as Lowry et al. (1951), using bovine serum albumin as standard.

\section{Statistical analysis}

Data are expressed as means \pm SEM values. Statistical analysis was carried out by one-way analysis of variance (ANOVA), followed by a Fisher's least significant difference multiple comparison test.

\section{Results}

\section{L-trans-Pirrolydine 2,4-dicarboxylate}

and 3-nitropropionic acid depolarize mitochondrial membrane potential but do not induce neuronal death

In our previous study, we have shown that incubation of cerebellar neurons with PDC $(500 \mu \mathrm{M})$ increases extracellular glutamate concentrations to values ranging from 18 to $35 \mu \mathrm{M}$ (García and Massieu 2001) without inducing neuronal death at least up to $4 \mathrm{~h}$ of incubation (García and Massieu 2003). However, in the presence of subtoxic concentrations of the mitochondrial toxin 3-NP, PDC triggers cell death (García and Massieu 2001, 2003). Now, we have investigated the mechanisms involved, and we first focused on mitochondrial membrane potential. Here, we show that inhibition of glutamate uptake with PDC induced a rapid, but moderate (by $\sim 30 \%$ ) decrease of $\Delta \psi_{\mathrm{m}}$ that was sustained for, at least, the following $4 \mathrm{~h}$ of incubation (Fig. 1a). Such a PDCdependent loss of $\Delta \psi_{\mathrm{m}}$ was NMDA receptor-mediated, as it was fully prevented by MK-801 (JC-1 fluorescence values, $1.21 \pm 0.11,0.80 \pm 0.09,1.11 \pm 0.10$, arbitrary units, for
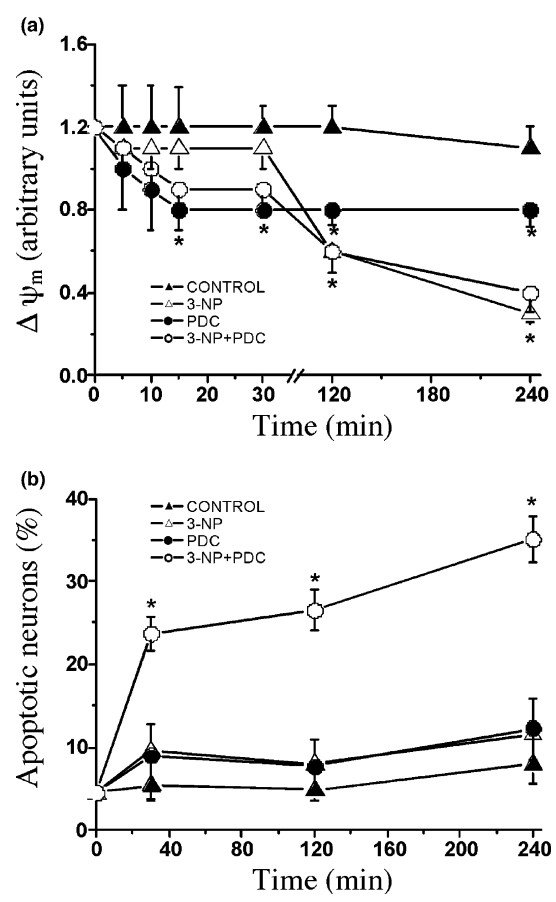

Fig. 1 Time course changes in (a) mitochondrial membrane potential $\left(\Delta \psi_{\mathrm{m}}\right)$ and (b) apoptotic death as measured in cerebellar neurons after inhibition of glutamate uptake (PDC, $500 \mu \mathrm{m}$ ), inhibition of succinate dehydrogenase (3-NP, $500 \mu \mathrm{m}$ ) or a combination of both. $\Delta \psi_{\mathrm{m}}$ and apoptosis (annexin $\mathrm{V}^{+} / 7-\mathrm{AAD}^{-}$cells) were measured by flow cytometry as described in Experimental Procedures. Results are mean \pm SEM values from four to six independent experiments. ${ }^{*} p<0.05$ vs. control. 3-NP, 3-nitropropionic acid; PDC, L-trans-pirrolydine 2,4-dicarboxylate. 
control, PDC and PDC + MK-801, respectively). On the other hand, the inhibition of succinate dehydrogenase activity with 3 -NP $(500 \mu \mathrm{M})$ did not alter $\Delta \psi_{\mathrm{m}}$ during the first $30 \mathrm{~min}$ of exposure, but induced a large depolarization after $2 \mathrm{~h}$ that declined further at $4 \mathrm{~h}$ (Fig. 1a). Co-incubation of PDC with 3-NP did not result in additional decay of $\Delta \psi_{\mathrm{m}}$ as compared with 3-NP alone (Fig. 1a), but enhanced apoptotic cell death from as soon as $30 \mathrm{~min}$ (Fig. 1b). In contrast, PDC or 3-NP treatments, alone, did not increase the percentage of apoptotic cells, at least up to $4 \mathrm{~h}$ of incubation (Fig. 1b).

\section{Mitochondrial membrane depolarization induced by 3-nitropropionic acid is dependent on NADH concentrations.}

As show in Fig. 1(a), treatment with 3-NP led neuronal $\Delta \psi_{\mathrm{m}}$ to collapse after $2 \mathrm{~h}$. In view that 3 -NP inhibits both succinate dehydrogenase and complex II of the mitochondrial respiratory chain, we next investigated whether 3-NP-induced mitochondrial depolarization was associated with the loss of reducing equivalents (NADH and $\mathrm{NADPH}$ ), which are involved in the maintenance of $\Delta \psi_{\mathrm{m}}$. As shown in Fig. 2(a), NADH concentrations diminished
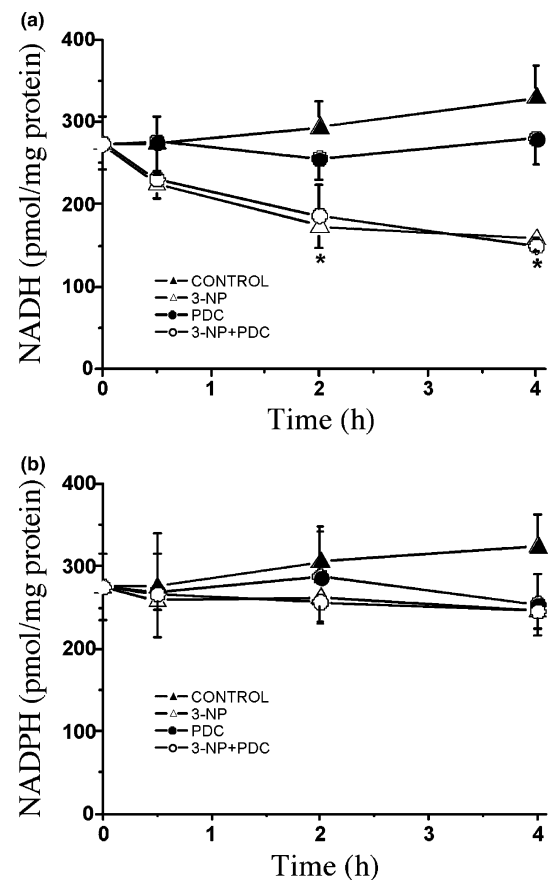

Fig. 2 Time course changes in (a) NADH and (b) NADPH, as measured in cerebellar neurons after inhibition of glutamate uptake (PDC, $500 \mu \mathrm{m}$ ), inhibition of succinate dehydrogenase (3-NP, $500 \mu \mathrm{m}$ ) or a combination of both. NADH and NADPH concentrations were measured by chemiluminiscence, as described in Experimental Procedures. Results are mean \pm SEM values from four to six independent experiments. ${ }^{*} p<0.05$ vs. control. 3-NP, 3-nitropropionic acid; PDC, L-trans-pirrolydine 2,4-dicarboxylate. significantly 2 and $4 \mathrm{~h}$ after 3-NP exposure, well correlating with the observed depolarization of the mitochondrial membrane (Fig. 1a). In contrast, exposure of neurons to PDC did not alter NADH concentrations at any of the time periods studied (Fig. 2a), and the coincubation of 3-NP with PDC had no additive effect on NADH concentrations when compared to those induced by 3-NP alone. NADPH concentrations were not altered by any of these treatments (Fig. 2b).

\section{Inhibition of glutamate uptake by L-trans-pirrolydine 2,4-dicarboxylate increases oxygen consumption in cerebellar granule neurons}

As shown in Fig. 1(a), PDC produced a brief and rapid $\Delta \psi_{\mathrm{m}}$ decrease that was sustained for the following $4 \mathrm{~h}$. In order to elucidate whether any further $\Delta \psi_{\mathrm{m}}$ collapse could have been prevented through the stimulation of the respiratory chain, the rate of oxygen consumption was monitored after $2 \mathrm{~h}$ of PDC exposure. Control neurons consumed oxygen at a rate of $0.31 \mathrm{nmol} \mathrm{O}_{2}$ per min per $0.5 \times 10^{6}$ cells (Table 1 ). However, incubation of cells with PDC triggered an increase in the rate of oxygen consumption by 1.4 -fold, whereas 3-NP had no effect (Table 1). To elucidate whether PDC-induced increase in oxygen consumption was associated to the activation of NMDA receptors, a group of cells were also incubated in the presence of the NMDA receptor antagonist, MK-801. As shown in Table 1, MK-801 prevented the increase in oxygen consumption induced by PDC. To ascertain whether such an increase in oxygen consumption was due to mitochondrial function, 3-NP was added to PDCtreated respiring cells, and we observed a 95\% blockade of oxygen consumption (not shown). In addition, we have previously reported that another mitochondrial toxin, sodium azide, potentiates PDC-mediated cellular death in a similar experimental paradigm (García and Massieu 2001). In view that an increase in oxidative stress up-regulates complex I activity, at least in glial cells (Vásquez et al. 2001), we sought to determine whether such a putative increase would

Table 1 Inhibition of glutamate uptake with L-trans-pirrolydine 2,4-dicarboxylate (PDC) increases the rate of oxygen consumption in cerebellar neurons

\begin{tabular}{ll}
\hline & $\begin{array}{l}\text { Rate of oxygen consumption } \\
(\mathrm{nmol} \mathrm{O}\end{array} / \mathrm{min} / 0.5 \times 10^{6}$ cells $)$ \\
\hline Control & $0.31 \pm 0.01$ \\
3-NP & $0.29 \pm 0.02$ \\
PDC & $0.44 \pm 0.04^{\star}$ \\
PDC + MK-801 & $0.21 \pm 0.07 \dagger$ \\
\hline
\end{tabular}

Oxygen consumption was determined after $2 \mathrm{~h}$ exposure of neurons to PDC (500 $\mu \mathrm{m})$ or 3-nitropropionic acid (3-NP: $500 \mu \mathrm{M})$. MK-801 (10 $\mu \mathrm{M})$ was incubated with PDC. Values are mean \pm SEM of three independent experiments. ${ }^{*} p<0.05$ vs. control values; $\uparrow p<0.05$ vs. PDC. 
account for the observed increased respiration rate. However, treatment of cells with PDC $(500 \mu \mathrm{M}, 2 \mathrm{~h})$ resulted in no change in the activity of complex I (control, $4.4 \pm 0.1$; PDC, $4.2 \pm 0.7 \mathrm{nmol} / \mathrm{min} / \mathrm{mg}$ of protein; $n=3$ ).

Inhibition of glutamate uptake with L-trans-pirrolydine 2,4-dicarboxylate induces reactive oxygen species production and decreases GSH concentrations

As an increase in the rate of oxygen consumption would enhance oxidative metabolism, we sought to investigate whether PDC treatment led to an increase in ROS production. Approximately $22 \%$ of control neurons showed carboxy-DCF fluorescence, indicating basal ROS production (Fig. 3a). However, the presence of PDC significantly increased the number of fluorescent cells as from $30 \mathrm{~min}$ of treatment, and remained elevated after 2 and $4 \mathrm{~h}$ (Fig. 3a). This effect was inhibited by catalase $(100 \mathrm{U} / \mathrm{mL})$ and by MK-801 $(10 \mu \mathrm{M})$ (Fig. 3b). In contrast, 3-NP alone did not increase the number of fluorescent cells at any of the times investigated (Fig. 3a). Furthermore, the exposure of neurons to PDC plus 3-NP did not increase the number of fluorescent cells when compared
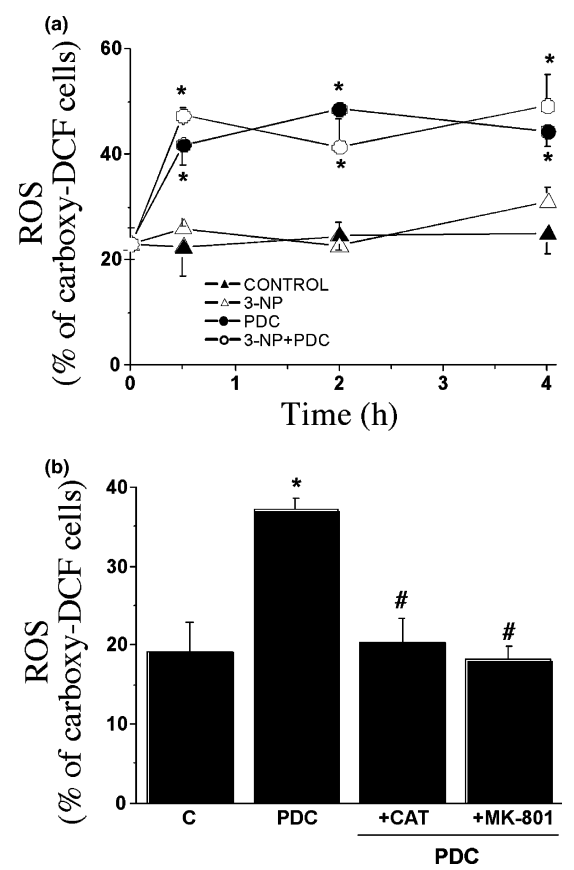

Fig. 3 Inhibition of glutamate uptake by PDC induces ROS production in cultured cerebellar granule cells. (a) ROS production were determined after exposure of cells to PDC $(500 \mu \mathrm{M})$ or 3-NP $(500 \mu \mathrm{m})$, either alone or in combination. (b) ROS production were also measured at $2 \mathrm{~h}$ after PDC $(500 \mu \mathrm{m})$ treatment, either in the absence or in the presence of catalase $(100 \mathrm{U} / \mathrm{mL})$ or MK-801 $(10 \mu \mathrm{m})$. ROS production was assessed by determination of oxidation products of carboxy-DCF. Data are mean \pm SEM values from three (carboxy-DCF) independent experiments. ${ }^{*} p<0.05$ vs. control; $\# p<0.05$ vs. PDC. CAT, catalase; $\mathrm{DCF}$, dichlorofluoroscein; 3-NP, 3-nitropropionic acid; PDC, L-transpirrolydine 2,4-dicarboxylate; ROS, reactive oxygen species.
Table 2 Effect of L-trans-pirrolydine 2,4-dicarboxylate (PDC) and 3-nitropropionic acid (3-NP) on superoxide anion production by cerebellar neurons, as assessed by hydroethidine fluorescence

Hydroethidine fluorescence

(\% of positive cells per field)

$\begin{array}{lc}\text { Control } & 2.3 \pm 0.9 \\ \text { PDC } & 5.2 \pm 1.2 \\ \text { 3-NP } & 5.6 \pm 0.3 \\ \text { PDC + 3-NP } & 10.3 \pm 1.5^{*}\end{array}$

Cells were treated with PDC $(500 \mu \mathrm{m}), 3-\mathrm{NP}(500 \mu \mathrm{m})$ or a combination of both for $2 \mathrm{~h}$, washed and further incubated in the presence of hydroethidine. After washing and fixing, cells were mounted and analyzed by fluorescence microscopy. Each value represent the mean \pm SEM values from four to six different cell culture preparations. ${ }^{*} p<0.05$ vs. control values.

with PDC alone (Fig. 3a). In order to ascertain whether superoxide anion was a major ROS component under our conditions, we next used hydroethidine, i.e. a fluorescent probe previously shown to specifically detect superoxide anion in cultured neurons (Bindokas et al. 1996). As shown in Table 2, $2 \mathrm{~h}$ after treatment, neither PDC nor 3-NP alone were sufficient to generate detectable superoxide, whereas the combination of PDC with 3-NP significantly increased the number of fluorescent cells. To investigate whether ROS production was associated with impairment of GSH status, GSH concentrations were determined in the same experimental conditions. As shown in Fig. 4(a), PDC treatment progressively decreased GSH concentrations, reaching the statistical significance after 2 and 4 h of exposure. In contrast, 3-NP treatment, alone, did not alter GSH concentrations (Fig. 4a). When 3-NP was combined with PDC, GSH was not further decreased when compared with PDC treatment alone (Fig. 4a). The decrease in GSH concentrations observed $2 \mathrm{~h}$ after PDC treatment was not prevented by superoxide dismutase $(100 \mathrm{U} / \mathrm{mL})$ or L-NAME $(1 \mathrm{~mm})$ (results not shown). However, it was partially prevented by catalase (100 U/mL) and MK-801 (10 $\mu \mathrm{M})$ (Fig. 4b).

\section{Discussion}

Glutamate uptake inhibition with PDC induced a rapid and modest $\Delta \psi_{\mathrm{m}}$ fall that was sustained further, whereas the inhibition of mitochondrial respiratory chain with 3-NP largely depolarized mitochondria in a delayed $(2 \mathrm{~h})$ manner. In contrast to 3-NP, PDC-mediated loss of $\Delta \psi_{\mathrm{m}}$ was not related to the loss of reducing equivalents and therefore to the impairment of mitochondrial electron flow, but rather to calcium influx into the mitochondria after activation of NMDA receptors. This result is in good agreement with the well-known role of calcium influx to the mitochondria in the $\Delta \psi_{\mathrm{m}}$ loss and excitotoxicity (Schinder et al. 1996; White and Reynolds 1996; Peng and Greenamyre 1998; Fiskum et al. 

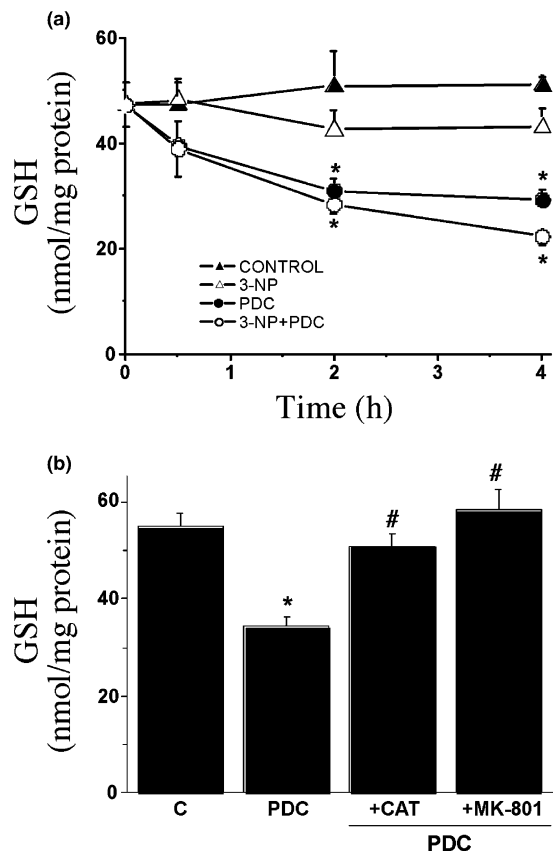

Fig. 4 Inhibition of glutamate uptake by PDC depletes GSH in cultured cerebellar granule cells. (a) GSH concentrations were determined after exposure of cells to PDC $(500 \mu \mathrm{m})$ or 3-NP $(500 \mu \mathrm{m})$, either alone or in combination. (b) GSH concentrations were also measured at $2 \mathrm{~h}$ after PDC (500 $\mu \mathrm{m})$ treatment, either in the absence or in the presence of catalase $(100 \mathrm{U} / \mathrm{mL})$ or MK-801 $(10 \mu \mathrm{M})$. GSH concentrations were determined enzymatically as described in Material and Methods. Data are mean \pm SEM values from six (GSH) independent experiments. ${ }^{*} p<0.05$ vs. control; $\# p<0.05$ vs. PDC. CAT, catalase; 3-NP, 3-nitropropionic acid; PDC, L-trans-pirrolydine 2,4-dicarboxylate.

1999; Duchen 2000; Nicholls et al. 2003). However, none of these treatments affected cell survival, at least during the $4 \mathrm{~h}$ investigated. Interestingly, apoptotic cell death was triggered only when both PDC and 3-NP were simultaneously present, despite no further decline in $\Delta \psi_{\mathrm{m}}$ was observed when compared to 3-NP treatment alone. Such a $\Delta \psi_{\mathrm{m}}$ loss would hence be associated with the widely held notion that excitotoxicity occurs through mitochondrial dysfunction leading to ATP depletion (Ankarcrona et al. 1995; Pang and Geddes 1997; Almeida and Bolaños 2001; García and Massieu 2003).

Interestingly, the dual inhibition of succinate dehydrogenase and complex II of the mitochondrial respiratory chain occurring in the cerebellar neurons exposed to 3-NP (García and Massieu 2001) was insufficient to trigger immediate $\Delta \psi_{\mathrm{m}}$ loss. Such $\Delta \psi_{\mathrm{m}}$ loss occurred only after $2 \mathrm{~h}$ of 3-NP treatment, and was well correlated with NADH, but not NADPH depletion, strongly suggesting that, during this time, $\Delta \psi_{\mathrm{m}}$ would be maintained at the expense of complex I-mediated NADH oxidation. Only when endogenous NADH content is exhausted, due to the inhibition of succinate dehydrogenase activity, the subsequent complex I dysfunction will fail to properly maintain $\Delta \psi_{\mathrm{m}}$. In any case, $\Delta \psi_{\mathrm{m}}$ loss induced under this condition does not appear to compromise neuronal survival, suggesting that mitochondrial depolarization, per se, would be insufficient to cause neuronal death.

Non-toxic glutamate receptor activation during PDC exposure partially decreased but did not disrupt completely $\Delta \psi_{\mathrm{m}}$. To understand the mechanism whereby $\Delta \psi_{\mathrm{m}}$ was not collapsed and cells survived to such mild glutamate receptor activation, we next investigated the rate of mitochondrial oxygen consumption. Cells responded to PDC treatment by increasing the rate of mitochondrial oxygen consumption. Such an increase in oxygen consumption would be associated with $\Delta \psi_{\mathrm{m}}$ maintenance, because $\Delta \psi_{\mathrm{m}}$ in PDC-treated cells was lost only when mitochondrial respiratory chain was inhibited. Furthermore, the stimulation of mitochondrial respiration was accompanied by enhanced ROS production and GSH depletion, in good agreement with previous studies reporting that superoxide anion would be formed during glutamate excitotoxicity (Lafón-Cazal et al. 1993; Dugan et al. 1995). However, no detectable superoxide was observed after $2 \mathrm{~h}$ with PDC alone, whereas it did increase ROS production, suggesting that superoxide may be rapidly transformed into hydrogen peroxide. In fact, catalase, but not superoxide dismutase, prevented PDC-mediated dichlorofluorescein fluorescence and GSH depletion. Moreover, the decrease in GSH might be associated with the recently described impaired GSH biosynthesis - a consequence of the lack of the GSH precursor, glutamate - in a similar model of excitotoxicity (Chen and Swanson 2003; Himi et al. 2003; Ré et al. 2003). However, this is not the case under our circumstances, because both GSH depletion and ROS production induced by PDC were prevented by MK- 801 . These results strongly suggest that ROS production and GSH depletion are the consequence of NMDA receptors activation by the glutamate accumulated in the extracellular medium.

In conclusion, our results suggest that the accumulation of endogenous extracellular glutamate after inhibition of its transporters induces a partial $\Delta \psi_{\mathrm{m}}$ loss that is compensated by the stimulation of mitochondrial respiratory chain activity, which leads to ROS production and GSH deficiency in a manner dependent on NMDA receptor activation. Such a compensative mechanism appears to support neuronal survival, unless there is concomitant mitochondrial respiratory chain deficiency hampering such a neuroprotective strategy. Prolonged inhibition of mitochondrial respiratory chain activity has been observed after cerebral ischemia (Anderson and Sims 1999) and in postmortem brain tissue samples obtained from Huntington's disease subjects (Gu et al. 1996; Browne et al. 1997). Moreover, the excitotoxicity associated with these pathologies has been suggested to be a consequence of decreased glutamate transport (Arzberger et al. 1997; Mitani and Tanaka 2003). These observations suggest that in addition to the expansion of the CAG codon in 
Huntingtin protein associated with Huntington's disease patients, an excitotoxic mechanism, probably precipitated by a progressive decline in mitochondrial function, might be involved in the pathogenesis of this disease (Zeron et al. 2001; Panov et al. 2002). Thus, our results may contribute to understanding the mechanisms involved in neuronal death associated with cerebral ischemia and certain neurodegenerative disorders, such as Huntington's disease.

\section{Acknowledgements}

This work was supported by M.C.Y.T. (SAF2001-1961/SAF20042038) and J.C. y L. (SA081/04) to JPB; FIS (03/1055) and J.C. y L. (SA020/02) to AA; IN203400 and IN222503 PAPIIT, UNAM to LM; and DGEP-UNAM and CONACYT 163330 fellowships to OG. We are grateful to Dr M. Delgado-Esteban and T. Montiel for excellent technical assistance.

\section{References}

Almeida A. and Bolaños J. P. (2001) A transient inhibition of mitochondrial ATP synthesis by nitric oxide synthase activation triggered apoptosis in primary cortical neurons. J. Neurochem. 77, 676-690.

Almeida A., Almeida J., Bolaños J. P. and Moncada S. (2001) Different responses of astrocytes and neurons to nitric oxide, the role of glycolytically generated ATP in astrocyte protection. Proc. Natl Acad. Sci. USA 98, 15 294-15 299.

Anderson M. F. and Sims N. R. (1999) Mitochondrial respiratory function and cell death in focal cerebral ischemia. J. Neurochem. 73, 1189-1199.

Ankarcrona M., Dypbukt J. M., Bonfoco E., Zhivotovovsky B., Orrenius S., Lipton S. A. and Nicotera P. (1995) Glutamate-induced neuronal death: a succession of necrosis or apoptosis depending on mitochondrial function. Neuron 15, 961-973.

Arzberger T., Krampfl K., Leimgruber S. and Weindl A. (1997) Changes of NMDA receptor subunit (NR1, NR2B) and glutamate transporter (GLT1) mRNA expression in Huntington's disease. An in situ hybridization study. J. Neuropathol. Exp. Neurol. 56, 440-454.

Benveniste H., Drejer J., Schousboe A. and Diemer N. H. (1984) Evaluation of extracellular concentrations of glutamate and aspartate in the rat hippocampus during transient cerebral ischemia monitored by intracerebral microdialysis. J. Neurochem. 43, 13691374.

Bindokas V. P., Jordan J., Lee C. C. and Miller R. J. (1996) Superoxide production in rat hippocampal neurons: selective imaging with hydroethidine. J. Neurosci. 16, 1324-1336.

Bittigau P. and Ikonomidou C. (1997) Glutamate in neurological diseases. J. Child Neurol. 12, 471-485.

Browne S., Bowling A., MacGarvey U., Baik M., Berger S., Muqit M. and Bird E. (1997) Oxidative damage and metabolic dysfunction in Huntington's disease: selective vulnerability of the basal ganglia. Ann. Neurol. 41, 646-653.

Cebers G., Cebere A., Wägner A. and Liljequist S. (1999) Prolonged inhibition of glutamate reuptake down-regulates NMDA receptor functions in cultured cerebellar granule cells. J. Neurochem. 72, 2181-2190.

Chen Y. and Swanson R. A. (2003) The glutamate transporters EAAT2 and EAAT3 mediate cysteine uptake in cortical neuron cultures. J. Neurochem. 84, 1332-1339.
Dringen R. and Hamprecht B. (1996) Glutathione content as an indicator for the presence of metabolic pathways of amino acids in astroglial cultures. J. Neurochem. 67, 1375-1382.

Duchen M. R. (2000) Mitochondrial and calcium: from cell signalling to cell death. J. Physiol. 529, 57-68.

Dugan L. L., Sensi S. L., Canzoniero L. M. T., Handran S. D., Rothman S. M., Lin T. S., Goldberg M. P. and Choi D. W. (1995) Mitochondrial production of reactive oxygen species in cortical neurons following exposure to $N$-methyl-D-aspartate. J. Neurosci. 15, 6377-6388.

Fiskum G., Murphy A.N. and Beal M.F. (1999) Mitochondria in neurodegeneration, acute ischemia and chronic neurodegenerative disease. J. Cereb. Blood Flow Metab. 19, 351-369.

García O. and Massieu L. (2001) Strategies for neuroprotection against L-trans-2,4-pyrrolidine dicarboxylate-induced neuronal damage during energy impairment in vitro. J. Neurosci. Res. 64, $418-428$.

García O. and Massieu L. (2003) Glutamate uptake inhibitor L-transpyrrolidine 2,4-dicarboxylate becomes neurotoxic in the presence of subthershold concentrations of mitochondrial toxin 3-nitropropionate, involvement of mitochondrial reducing activity and ATP production. J. Neurosci. Res. 74, 956-966.

García-Nogales P., Almeida A. and Bolaños J. P. (2003) Peroxynitrite protects neurons against nitric oxide-mediated apoptosis. J. Biol. Chem. 278, 864-874.

Greene J. and Greenamyre J. (1995) Exacerbation of NMDA, AMPA, and L-glutamate excitotoxicity by the succinate dehydrogenase inhibitor malonate. J. Neurochem. 64, 2332-2338.

Gu M., Gash M. T., Mann V. M., Javoy-Agid F., Cooper J. M. and Schapira A. H. V. (1996) Mitochondrial defect in Huntington's disease caudate nucleus. Ann. Neurol. 39, 389-399.

Hempel S. L., Buettner G. R., O’Malley Y. Q., Wessels D. A. and Flaherty D. M. (1999) Dihydrofluorescein diacetate is superior for detecting intracellular oxidants, comparison with $2^{\prime}, 7^{\prime}$-dichlorodihydrofluorescein diacetate, 5(and 6)-carboxy-2', $7^{\prime}$-dichlorodihydrofluorescein diacetate, and dihydrorhodamine 123. Free Rad. Biol. Med. 27, 146-159.

Himi T., Ikeda M., Yasuhara T., Nishida M. and Morita I. (2003) Role of neuronal glutamate transporter in the cysteine uptake and intracellular glutathione levels in cultured cortical neurons. J. Neural Transm. 110, 1337-1348.

Lafón-Cazal M., Pietri S., Culcasi M. and Bockaert J. (1993) NMDAdependent superoxide production and neurotoxicity. Nature 364, 535-537.

Lowry O. H., Rosebrough N. J., Lewis-Farr A. and Randall R. J. (1951) Protein measurement with the Folin phenol reagent. J. Biol. Chem. 193, 265-275.

Massieu L., Morales-Villagrán A. and Tapia R. (1995) Accumulation of extracellular glutamate by inhibition of its uptake is not sufficient for inducing neuronal damage, an in vivo microdialysis study. J. Neurochem. 64, 2262-2272.

Massieu L., Gómez-Román N. and Montiel T. (2000) In vivo potentiation of glutamate-mediated neuronal damage after chronic administration of the glycolysis inhibitor iodoacetate. Exp. Neurol. 165, 257-267.

Mitani A. and Tanaka K. (2003) Functional changes of glial glutamate transporter GLT-1 during ischemia, an in vivo study in the hippocampal CA1 of normal mice and mutant mice lacking GLT-1. J. Neurosci. 23, 7176-7182.

Nicholls D. G., Vesce S., Kira L. and Chalmers S. (2003) Interactions between mitochondrial bioenergetics and cytoplasmic calcium in cultured cerebellar granule cells. Cell Calcium 34, 407-424.

Novelli A., Reilly J. A., Lysko P. G. and Henneberry R. C. (1988) Glutamate becomes neurotoxic via the $N$-methyl-D-aspartate 
receptor when intracellular energy levels are reduced. Brain Res. 451, 205-212.

Pang Z. and Geddes J. W. (1997) Mechanism of cell death induced by the mitochondrial toxin 3-nitropropionic acid, acute excitotoxic necrosis and delayed apoptosis. J. Neurosci. 17, 3064-3073.

Panov A. V., Gutekunst C.-A., Leavitt B. R., Hayden M. R., Burke J. R., Strittmatter W. J. and Greenamyre J. T. (2002) Early mitochondrial calcium defects in Huntington's disease are a direct effect of polyglutamines. Nat. Neurosci. 5, 731-736.

Peng T. I and Greenamyre T. (1998) Privileged access to mitochondria of calcium influx through $\mathrm{N}$-methyl-D-aspartate receptors. Mol. Pharmacol. 53, 974-980.

Ragan C. I., Wilson M. T., Darley-Usmar V. M. and Lowe P. N. (1987) Subfractionation of mitochondria and isolation of the proteins of oxidative phosphorylation, in Mitochondria. A Practical Approach (Darley-Usmar, V. M., Rickwood, D. and Wilson, M. T., eds), pp. 79-112. IRL Press, London.

Ré D. B., Boucrat J., Samuel D., Birman S., Kerkerian-Le Goff L. and Had-Aissouni L. (2003) Glutamate transport alteration triggers differentiation-state selective oxidative death of cultured astrocytes: a mechanism different from excitotoxicity depending on intracellular GSH contents. J. Neurochem. 85, 11591170 .
Rossi D. J., Oshima T. and Attwell D. (2000) Glutamate release in severe brain ischaemia is mainly by reversed uptake. Nature 403, 316321.

Sánchez-Carbente M. R. and Massieu L. (1999) Transient inhibition of glutamate uptake in vivo induces neurodegeneration when energy metabolism is impaired. J. Neurochem. 72, 129-138.

Schinder A. F., Olson E. C., Spitzer N. C. and Montal M. (1996) Mitochondrial dysfunction is a primary even in glutamate neurotoxicity. J. Neurosci. 16, 6125-6133.

Tietze F. (1996) Enzymatic method for quantitative determination of nanogram amounts of total and oxidized glutathione, applications to mammalian blood and other tissues. Anal. Biochem. 27, 502522.

Vásquez O. L., Almeida A. and Bolaños J. P. (2001) Depletion of glutathione up-regulates mitochondrial complex I expression in glial cells. J. Neurochem. 76, 1593-1596.

White R. J. and Reynolds I. J. (1996) Mitochondrial depolarization in glutamate-stimulated neurons, an early signal specific to excitotoxin exposure. J. Neurosci. 16, 5688-5697.

Zeron M. M., Chen N., Moshaver A., Ting-Chun Lee A., Wellington C. L., Hayden M. R. and Raymond L. A. (2001) Mutant huntingtin enhances excitotoxic cell death. Mol. Cell. Neurosci. 17, 41-53. 